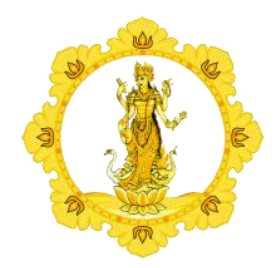

KALANGWAN

JURNAL PENDIDIKAN AGAMA, BAHASA DAN SASTRA

Vol. 11 No. 1 Maret 2021

\begin{tabular}{l|l|l|}
\hline p-ISSN : 1979-634X & e-ISSN : 2686-0252 & http://ejournal.ihdn.ac.id/index.php/Kalangwan
\end{tabular}

\title{
A NILAI RELIGI DALAM GEGURITAN MANIGUNA
}

\section{Oleh :}

Gek Diah Desi Sentana, I Wayan Dharma Suniarmika, Ni Ketut Ayu Nadia Sari Universitas Hindu Negeri I Gusti Bagus Sugriwa Denpasar

E-mail: geksentana@uhnsugriwa.ac.id

Diterima 23 Januari 2021, direvisi 25 Januari 2021, diterbitkan 31 Maret 2021

\begin{abstract}
The existence of Balinese literary works until now still has a place in the hearts of Balinese literary lovers, so that the existence of Balinese literary works has lived along with the times. There are many ways a writer can express his thoughts and ideas, one of which is by writing a literary work in the form of a geguritan. Balinese purwa (classical) literary works need to be preserved, nurtured and developed, because they contain noble values which are very important, meaning for the life of the people, especially the Balinese. The value theory from Yudibrata is used to reveal the importance of Geguritan Maniguna as a classic literature that records culture from a long period of time and contains various cultural paintings, ideas, ethics, advice, entertainment and including religious life, especially regarding religious values that exist. inside it.
\end{abstract}

\section{Keywords: Geguritan, Maniguna, Nilai, Religi}

\section{PENDAHULUAN}

Agama berasal dari bahasa sansekerta, dari akar kata "gam", yang berarti pergi. Kalau "gam" diberi awalan "a", menjadi "agam", yang berarti kebalikan dari pergi yaitu datang, dan bila diberi akhiran "a", kemudian menjadi kata "Agama", sehingga agama artinya adalah kedatangan (Punyatmadja, 1992:1). Agama merupakan suatu keyakinan yang sangat fundamental yang dapat membimbing manusia untuk mencapai kebahagiaan dan kesempurnaan. Oleh karena itu ajaran suci agama cenderung kepada pendidikan susila dan budi pekerti manusia yang bukan berakal dan memberi ilmu pengetahuan yang banyak. Agama berusaha membina umatnya untuk menjadi manusia susila dan bukan menjadi sarjana yang cerdik tetapi curang dan munafik (Punyatmadja, 1992:18). 
Keyakinan terhadap Tuhan telah menyatu dengan jiwa dan raga orang Hindu. Keyakinan orang Hindu dengan adanya Tuhan/Ida Sanghyang Widhi Wasamembawa satu keyakinan yang disebut Dharma (kebenaran). Kebenaran yang mutlak yang menuntun manusia untuk mencapai kesempurnaan hidup lahir Bhatin (moksartham jagadhitaya ca iti Dharma) yang artinya Dhmrma atau Agama itulah sumber utama untuk mencapai moksa (moksarthem) dan mencapai kesejahteraan makhluk hidup (jagdhita).Moksa juga disebut "mukti" artinya mencapai kebebasan jiwatman atau kebahagian rohani yang langgeng (Upadesa, 1989:9).

Secara umum agama Hindu di Indonesia dilaksanakan dalam tiga aspek sekaligus. Ketiga aspek agama itu adalah: tattwa (filsafat), susila (tata susila), dan upacara (ritual). Ketiga unsur tersebut diibaratkan seperti telur, upacara adalah kulit telurnya, susila adalah putih telurnya, dan tattwa adalah kuning telurnya. Telur akan dapat menetas dengan baik menjadi ayam, apabila ketiga unsur tersebut dapat berfungsi dengan baik. Demikian pula dengan kepercayaan manusia dengan agama akan mendatangkan kebahagiaan, jika manusia memiliki tiga hal yaitu iman yang teguh kepada Tuhan, etika yang baik terhadap sesama, dan perhatian yang cukup terhadap lingkungan (Santeri, 2000: 96).

\section{METODE}

Penelitian ini adalah penelitian kualitatif, dimana data utamanya adalah teks geguritan maniguna dan data sekundernya adalah tulisan yang terkait dengan penelitian ini. Teori yang dugunakan adalah teori nilai menurut Yudibrata (dalam Atmaja, 1988: 1820) merumuskan nilai agama meliputi nilai religius, nilai magis, kepercayaan, dan nilai spiritual.

\section{PEMBAHASAN}

Religius mencakup kepercayaan dan peristiwa yang dialami oleh seseorang yang mendasari semua tindakannya pada ajaran tentang ketuhanan.Orang yang mengakrabi tentang ketuhanan dalam aktivitas kelembagaannya, ditata oleh agama. Nilai religius yang terkandung dalam karya sastra Geguritan Maniguna dapat diketahui dari peristiwa-peristiwa yang dialami oleh tokoh Maniguna terdapat kekuatan gaib yang ditimbulkan oleh alam. Dalam Geguritan Maniguna dapat dilihat dengan jelas bahwa Maniguna yang telah meninggal karena dibunuh oleh Raja Naranata dan Raja Canda dapat dihidupkan kembali. Ketika Diah Arini menemukan mayat Maniguna, hati Diah Arini menjadi sangat sedih dan memohon kepada Tuhan agar suaminya dapat hidup kembali. Tiba-tiba datanglah dua ekor ular yang merupakan penjelmaan dari Tuhan, yang memberikan petunjuk pada Diah Arini untuk menghidupkan kembali suaminya. Hal ini dapat dilihat pada kutipan berikut ini:

durung puput asasambat, dadyana mayan ing Hyang Widhi masih, katon ula istri-kakung, akrama ring janggala, mapulilit garini ngemasin antu, sang kakung kagyat mulinga, Ngambil taru ngusadani (Geguritan Maniguna, Pupuh Pangkur bait 31)

gelis urip wus sinembar, paripurna tingkahe kadi nguni, Raris ical ngungsi semput, Sang Dyah manyadya nulad, ngambil taru cinanggeman dekdek sampun, kasembar raris sang pejah, Anuli urip matangi (Geguritan Maniguna, Pupuh Pangkur bait 32)

\section{Terjemahan}

belum selesai menggambar kata, tibatiba berkelebat bayangan tuhan menjelma, nampak ular jantan-betina, memadu kasih ditanah, tiba-tiba ular yang betina sudah mati, si jantan terkejut melihatnya, lalu mengambil sebatang kayu untuk mengobati (Geguritan Maniguna, Pupuh Pangkur bait 31

Setelah selesai diobati ular tersebut kembali hidup setelah disembur, tanpa cela layaknya seperti semula, kemudian 
hilang menuju semak-semak, Dyah Arini bersedia menirunya, ngambil kayu tersebut dikunyah sampai lumut, lalu Sang Maniguna disembur, kemudian Sang Maniguna hidup lalu bangun (Geguritan Maniguna, Pupuh Pangkur bait 32)

Dari kutipan diatas menggambarkan suatu kejadian yang benar-benar muzijat dari Tuhan, dengan petunjuk dari Tuhan melalui penjelmaan dua ekor ular tersebut, Maniguna yang sudah meninggal dapat dihidupkan kembali dengan diobati menggunakan sebatang pohon yang dikunyah langsung disemburkan ke mayat Maniga. Setelah Maniguna hidup seperti semula, Diah Arini menceritakan kejadian yang sudah terjadi, akhirnya Manigunapun menyuruh Diah Arini untuk menyimpan kayu yang telah bisa menghidupkan kembali.

Kejadian serupa terulang lagi ketika Diah Arini sedang kebingungan mencari mayat suaminya yang telah dibuang di tengah lautan. Oleh Sang Raja Canda. Diah Arini tak henti-hentinya memohon kepada Tuhan agar ditemukan kembali dengan suaminya.Akhirnya Diah Arini dapat petunjuk dari Tuhan melalui petir yang menunjukkan arah keberadaan suaminya. Hal ini dapat dilihat pada kutipan berikut:

tan mari masasambatan, Mangane sang sampun lalis, Cingak tityang duhka bara, Iriki ring wana giri, Lalutan sih Hyang Widhi, Maweh lara tan awanuh, Kewala patutuhang, Mangde panggih sang alalis, Inggih ratu suka mati makaronang. (Geguritan Maniguna, Pupuh Sinom bait 16)

"ah ah kita urip ingwang, apa sukanta ring urip, Nah jiwa Si kalakanta, rampasana den agate, Sang Ayu maningali, Suteja awor ing limu, sahatatit kumedap-dap, Sawang tingal mangulapin, Kadi tuduh, Ri ana sang sampun lina. (Geguritan Maniguna, Pupuh Sinom bait 18) pamargine mangenggalang, ngetut kumedap ing tatit, tan ucapan sireng alas Sampun rawuh ring pasisi, Nuhut pasisi sedih, Mangulame sang abagus, kacingak makembangan, Sang ahayu manyagjagin, Tur kasawup, Raris bakta kadahetan. (Geguritan Maniguna, Pupuh Sinom bait 19)

Terjemahan:

tiada hentinya mengigau, memikirkan orang yang sudah tiada, lihatlah aku duka lara nestapa, disini dalam hutan gunung, lalu terlalu tidak diberkati tuhan, memberikan duka lara tak habishabisnya, mohon ditunjukkan, agar kuberjumpa dengan orang yang sudah tiada, ya Tuhanku, lebih baik mati berduaan (Geguritan Maniguna, Pupuh Sinom bait 16)

wahai engkau jiwaku, apakah kesenanganmu hidup, wahai jiwa $\mathrm{Si}$ kalantaka, sepatlah cabut jiwaku, Dyah Arini lalu melihat, sinar terang menyatu dengan awan tipis, dibarengi dengan kilat yang kebyar-kebyar, kalau dilihat menyilaukan, bagaikan petunjuk, tentang keberadaan orang yang sudah tiada (Geguritan Maniguna, Pupuh Sinom bait 18)

perjalanannya dipercepat, mengikuti gemerlapnya sinar kilat, tidak diceritakan Dyah Ayu dihutan, sudah sampai ditepi samudra, kesedihannya menelusuri tepi lautan, mengenang Sang Maniguna, tiba-tiba dilihat mengambang, Dyah Ayu menjemputnya, lalu di pangku, lalu dibawa kedaratan (Geguritan Maniguna, Pupuh Sinom bait 19)

Berdasarkan kutipan di atas dapat diceritakan Diah Arini tak henti-hentinya memohon kepada Tuhan agar dia diberikan petunjuk oleh Tuhan agar dia bisa menemukan Mayat suaminya yang sedang 
dibuang ketengah laut oleh Raja Canda. Berbagai rintangan yang telah dilalui ditengah hutan, semua binatang untuk berlomba memakan Sang Ayu, ketika itu Diah Arini sudah pasrah karena sudah tidak tahan menahan penderitaan. Diah Arini memohon kepada tuhan Agar nyawanya dicabut biar dia ikut meninggal, tiba-tiba ada sinar petir memberikan petunjuk untuk memberi tau keberadaan mayat Maniguna. Akhirnya mayat Maniguna ditemukan mengapung dilaut. Akhirnya Diah Arini kembali mengobatinya dengan kayu yang dimiki. Kemudian Maniguna hidup kembali.

Etika merupakan pengetahuan tentang kesusilaan. Kesusilaan berbentuk kaidahkaidah yang berisi larangan-larangan atau suruhan-suruhan untuk berbuat sesuatu. Dengan demikian dalam etika terdapat ajaran tentang perbuatan yang baik dan perbuatan yang buruk.Secara etimologi etika berasal dari bahasa Yunani. Ethos yang berarti watak kesusilaan atau adat, dalam kamus umum bahasa Indonesia etika diartikan ilmu pengetahuan tentang azas-azas akhlak (moral), dari pengertian kebahasaan ini terlihat bahwa etika berhubungan dengan upaya menentukan tingkah laku manusia (Atmaja, 2010: 8).

Susila adalah nama lain dari kata Ethika dan Moral, merupakan dua buah kata dalam kehidupan yang dipergunakan silih berganti untuk maksud yang sama. Ethika berasal dari bahasa Yunani, dari kata ethos yang berarti karakter kesusilaan atau adat. Sedangkan moral berasal dari bahasa latin, dari kata Mos yang dalam bentuk jamaknya mores yang berarti cara hidup atau adat. Dengan demikian dapat dikatakan bahwa kata ethika dan moral memiliki arti yang sama. Di dalam perkembangan selanjutnya, ethika (ethics) merupakan sebuah bidang kajian tentang sistem nilai-nilai (moral) yang ada.Sedangkan moral adalah perilaku atau perbuatan manusia itu sendiri (Sudirga, 2004: 106).

Etika merupakan satu ilmu yang mempelajari tentang tata nilai, tentang baikburuk suatu perbuatan, apa yang harus dijalani dan dihindari sehingga tercipta suatu tatanan hubungan antara manusia dengan masyarakat yang dianggap baik, serasi, rukun, dan bermanfaat bagi pribadi seseorang, masyarakat dimana seseorang bertempat tinggal, lingkungan, dan alam sekitarnya yang perlu dipertahankan (Pudja, 1985: 57). Seperti yang tertulis dalam kitab suci Sarasamusccaya bahwa ajaran etika Hindu dengan melihat hubungan antara karma (tingkah laku perbuatan) dengan phala (pahala atau akibat) dari perbuatan yang dikerjakan. Dalam kitab Sarasamusccaya ayat (16. 160) disebutkan bahwa:

çilam pradhānam puruse

Tadyasyeha pranacyati

Na tasya fiwitendrtho

Buhçilam kinprayojanam

Terjemahan:

Sila adalah yang paling utama 1) pada diri manusia; (jika) ada manusia yang tidak susila, apakah maksud orang itu dengan hidupnya (demikian), dengan kekuasaan, dengan kebijaksanaan, sebab akan sia-sia itu semuanya, jika tidak ada kesusilaan pada pelaksanaannya(Pudja, 1979: 89-90).

Kutipan sloka di atas, menjelaskan ajaran etika Hindu berkaitan erat dengan karma phala.Baik buruk suatu perbuatan tidak hanya diukur dari tujuan perbuatan yang dilakukan tetapi akibat yang lebih luas pada masyarakat umum. Dengan berpedoman pada ajaran Subha AsubhaKarma tujuan digariskan untuk hal mencapai hayu (rahayu)-nya jagat (dunia atau masyarakat) (Pudja, 1979: 88)

Melihat pengertian diatas, dapat disimpulkan bahwa etika merupakan pengetahuan yang dipakai pedoman dalam bersopan santun, baik dalam pergaulan, etika hendaknya selalu diperhatikan dalam membina hubungan antara sesama, baik keluarga, sanak saudara, ataupun masyarakat luas, dan dengan tetap memperhatikan hubungan sebab akibat atau karma phala. 
Dalam Geguritan Maniguna nilai etika ini digambarkan salah satunya adalah sikap hormat. Sikap hormat merupakan etika untuk menghargai seseorang atau dengan manusia, dan juga hormat bakti kehadapan Ida Sang Hyang Widhi. Sikap hormat seseorang dapat dilihat dari sikap dan budi bahasanya, sebelum melihat kepribadiannya lebih jauh. Seperti kutipan berikut:

lalu lalista matilar, nanging jantos ingwang ring titi gal-ugil, malih ring margane kebus, yadyan ring kama loka, mangda tumut makaronan saleng tuntun, duh hyang dasa lokapala, cingak tityang satyeng laki.(Geguritan Maniguna, Pupuh Pangkur bait 30)

\section{Terjemahan:}

sampai hati meninggalkan, tetapi tunggulah aku pada titi ugal-agil, dan pada jalan yang panas, walaupun di neraka, supaya turut berduaan saling bergandengan, ya Tuhan penguasa perjuru Dunia, lihatlah hambamu yang setia pada suami.(Geguritan Maniguna, Pupuh Pangkur bait 30).

Dari kutipan di atas, dapat dilihat sikafhormat Diah Arini terhadap Tuhan. Diah Arini selalu menyebut nama Tuhan dan memohon kepada Tuhan agar dia tidak dipisahkan dengan orang yang disayangi. Disamping kutipan itu, terdapat juga kutipan sikap hormat Maniguna dengan istrinya Diah Arini. Hal tersebut dapat dilihat dalam kutipan berikut:

dewa sang kadi Hyang Giri Putri, Tuwah I Dewa, paragan utama, ampura kakanta mangke, langgya mapamit mantuk, maninggalin I Dewa mangkin, sampunang salit arsa, boya tityang ratu, saking tamilar pitresna, ring I dewa, kewala ngeton byang suri, kalih Ida I bapa.(Geguritan Maniguna, Pupuh Dangdang bait 22)

akuweh wuwus sang amamuwit mulih, ring sang kalih, sampun masumpah hyang, padangamel pitresnane, Maniguna lumaku, nanging kari kahalin - alin, Sang maninggal, pada mangu-mangu, asing ton nggawe byapara, palakune, tankocapan karyeng margi, amanggih kadurmanggala (Geguritan Maniguna, Pupuh Dangdang bait 25)

Terjemahan:

dewiku bagaikan Sang Hyang Giri Putri, hanya dewiku, sosok yang paling utama, maafkan kini kekandamu, lancang aku mohon pamit pulang, aku meninggalkan dewiku sekarang, janganlah dewiku salah paham, aku bukan dewi, karena meninggalkan cinta kekasihku, kepadamu dewi, hanya kanda teringat dengan ibu suri, dan teringat dengan ayah anda.(Geguritan Maniguna, Pupuh Dangdang bait 22)

Banyak kalau dibicarakan orang yang mohon pamit, pada kedua sijoli tersebut, keduanya sudah bersumpah, sama-sama memegang janji, sang maniguna lalu berjalan, tetapi masih tetap terkenang, orang yang ditinggalkan melongo dan bengong, apa dilihat menyusahkan, perjalannya, tidak diceritakan dulu, mengalami pirasat buruk.(Geguritan Maniguna, Pupuh Dangdang bait 25)

Nilai Etika dalam Geguritan Maniguna terjadi ketika sikap hormat Maniguna terhadap istrinya Diah Arini. Dengan perkataan yang halus Maniguna mengungkapkan secara jujur tentang jati dirinya kepada istrinya bahwa ia sesungguhnya adalah putra raja dari Madraka. Maniguna sekarang berkehendak kembali ke istana untuk menemui ayah dan ibunya, maka dari itu Maniguna memohon pamit kepada Diah Arini agar diberi ijin untuk bertemu dengan ibu dan ayahnya. Setelah Maniguna dan Diah Arini memegang janji akhirnya Diah Arini mengijinkan Maniguna untuk pergi menemui ibu dan ayahnya.Selain itu sikap 
hormat Diah Arini dengan Raja Naranata terlihat pada kutipan di bawah ini:

sang ayu masawur aris, wireh mula jati pradnyan, pramangke mangawe naya, singgih sadnya Sri Narendra, ampuna kang kawula, langgya amidi sang prabu, Wenten kakan tityang ical (Geguritan Maniguna Pupuh Smarandana bait 2)

Terjemahan:

dyah arini lalu menjawab, karena memang dia pintar, mendadak membuat daya upaya, duh paduka tuanku raja, maafkanlah hambamu ini, hamba mohon pada paduka, hamba mempunyai saudara tua menghilang. (Geguritan Maniguna Pupuh Smarandana bait 2)

Dari kutipan diatas menggambarkan sikap hormat Diah Arini terhadap Raja Naranata, ketika itu Diah Arini diajak untuk menemani tidur, namun Diah Arini mempunyai akal dengan mengatakan bahwa dirinya telah mempunyai kakak bernama Maniguna. Ketika itu Diah Arini memohon dengan Sang raja untuk mencarikan saudaranya yang bernama Maniguna. Setelah bertemu dengan Maniguna, Diah Arini berjanji akan menyerahkan dirinya sepenuhnya kepada Sang Raja. Didalam hal tersebut membuktikanmereka memiliki etika, dan sebagai cermin jati diri.

Nilai logika meliputi nilai intelektual, ilmiah (pengetahuan) dan nilai empiris (Yudibrata dalam Atmaja, 1980: 18-20).Nilai logika dalam Geguritan Maniguna yakni nilai intelektual, dimana tokoh Diah Arini diceritakan memiliki intelektual atau kemampuan berpikir yang tinggi.Dengan memiliki kemampuan yang tinggi Diah Arini pintar mencari akal agar dirinya tidak bisa dijadikan suami Sang Raja Naranata. Hal tersebut dapat dilihat dibawah ini:

sang ayu masawur aris, wireh mula jati pradnyan, pramangke mangawe naya, Singgih sadnya Sri Narendra, ampuna kang kawula, langgya amidi sang Prabu, Wenten kakan tityang ical (Geguritan Maniguna, Pupuh Semarandana bait 2)

maniguna akakasih, yan sampun kasidan prapta, rika manehta Sang katon, asrahaken jiwa-raga, Sang Nata raris ngucap, Mangke sun kinon angruruh, Ayuwa sira manangsaya (Geguritan Maniguna, Pupuh Semarandana bait 3)

Terjemahan:

dyah arini lalu menjawab, karena memang dia pintar, mendadak membuat daya upaya duh paduka tuanku raja, maafkanlah hambamu ini, hamba mohon pada paduka, hamba mempunyai saudara tua menghilang. (Geguritan Maniguna, Pupuh Semarandana bait 2)

saudaraku bernama Maniguna, kalau sudah dapat kembali pulang, pada saat itu hamba tuanku, menyerahkan jiwa ragaku, Sri paduka lalu bersabda, sekarang kuperintahkan prajuritku untuk mencari, janganlah adinda berkecil hati.(Geguritan Maniguna, Pupuh Semarandana bait 3)

Dari kutipan diatas menceritakan bahwa ketika Sang Raja Naranata mengajak Diah Arini untuk menemani tidur, Diah Arini membuat akal untuk menolak Sang Raja. Diah Arini berpura-pura mempunyai seoarang kakak kandung yang hilang bernama Maniguna, Sang Raja disuruh mencari Maniguna, ketika kakaknya Maniguna sudah ditemukan Diah Arini berjanji akan menyerahkan dirinya dengan sepenuhnya kepada Sang Raja Naranata. Akhirnya Sang Raja langsung menyuruh prajuritnya untuk mencarikan Maniguna. Ketika Maniguna sudah ditemukan, akhirnya Maniguna diajak ke istana untuk dipertemukan dengan Diah Arini.Sampai di istana ketika Diah Arini dipertemukan dengan Maniguna tiba-tiba turun hujan angin yang sangat kencang, 
semua prajurit dan Sang Raja menyelamatkan diri masing-masing.Diah Arini akhirnya melarikan diri bersama Maniguna.

Nilai-nilai intelektual atau kemampuan berpikir berikutnya terdapat dalam Geguritan Maniguna, juga dapat diketahui dari Sang Raja Canda yang mulai merayu Diah Arini, disaat Sang Raja merayu Diah Arini menjadi gugup, ketika itu Diah Arini muncul pemikirannya untuk memuji-muji istana dan merayu Sang Raja, Seperti yang tampak dalam kutipan berikut:

gawok tityang mangatonang, becik purine iriki, tan bineng smaralokal pamupulan sarwa lewih, pantes ratun ratun ing bumi, Paranata padanungkul, manyerahang sanagara, sami tinut saha bakti, lintang kasub, apa maka pangasoran.(Geguritan Maniguna, pupuh Sinom bait 12)

duh dewa sang kadi sinwam, ada ne kaliliran kris, tan papasah ri kakantal lewih guna mahasakti, panugrahan Hyang Widhi, yan tabahang api murub, Dadi ngeseng sarwa galak, Sampun wengi sane mangkin, nunas ratu, Munggah mungguh ing pakasutan.(Geguritan maniguna, pupuh Sinom, bait 13)

dyah arini sayan merang, eling ri pejah sang swami, sampun anyud ring sagara, kebus idepe luwir apui, kabatek satyeng laki, Raris dane ngunus duhung, mijil geni anngorob, kawegan Sang Narapati, tur kasuduk, sang nata geseng saksana.(Geguritan Maniguna, Pupuh Sinom bait 14)

Terjemahan:

heran hamba melihatnya, indahnya keraton disini, tak ubahnya di smara loka, perkumpulan segala yang indah, wajar jadi Ratu di Negara, semua rajaraja takluk menyerahkan wilayah kekuasaan, semua menurut dan menyembah, lewat terkenal, siapakah akan menunjukkan.(Geguritan maniguna, pupuh Sinom bait 12)

duhai dinda bagaikan bunga hati, ada isini keris pusaka, tidak pernah pisah dari kakanda, mantra guna dan maha sakti/ anugrah dari tuhan yang maha esa, kalau diarahkan mengeluarkan api yang besar dan berkobar, akan membasmi segala macam yang galak, sudah itu tiba malam hari sekarang, mohon dewiku, naik kebalai ranjang tempat peraduan. (Geguritan maniguna, pupuh Sinom, bait 13)

dyah arini makin marah, teringat dengan wafatnya sang suami, yang telah dihayutkan dilautan, pikirannya panas bagaikan api, kalena setia kepada suami, lalu Sang Dyah mencabut keris, keluar api berkobar, gelagapan Sri paduka raja, lalu ditusuk, Sang Nata terbakar seketika.(Geguritan Maniguna, Pupuh Sinom bait 14)

Kutipan diatas menjelaskan bahwa Diah Arini muncul idenya untuk merayu Sang Raja Canda dengan mengatakan bahwa istana yang dimiliki oleh Sang raja benar-benar indah dan megah. Semua para raja nurut dan menyembah Raja Canda dan semua raja-raja takluk terhadap Raja Canda, hati Sang Raja senang dan menjadi luluh ketika dirayu oleh Diah arini. Akhirnya Sang Raja menceritakan pusaka yang dimiliki, Sang Raja menceritakan tentang keris yang sakti, yang bisa mengeluarkan api. Karena Diah arini ingat dengan suaminya yang telah dibunuh oleh sang raja.

Akhirnya munculah pikiran Diah Arini untuk membunuh Raja Canda dengan menggunakan keris yang telah dimiliki Sang Raja. Dari kutipan diataslah bahwa Diah Arini benar memiliki pemikiran yang pintar dan memiliki banyak akal untuk melindungi dirinya sendiri dan melindungi suaminy.

Kesetian berasal dari kata setia (satya) mendapat konfliks ke-an menjadi kesetiaan yang berarti setia/kejujuran. Satya memegang 
peranan yang sangat penting didalam ajaran sastra tentang kerohanian kebahagiaan akhirat (sorga) serta penjelmaan yang baik dan kelepasan atau moksa (Bajrayasa dkk, 1982: 21).

Dalam Agama Hindu kita mengenal lima macam satya yang sering disebut dengan Panca Satya. Panca Satya memang berpegang teguh pada kejujuran.Satya merupakan bagian ketiga dari Panca Yama Brata, dimana kata satya berasal dari urat kata"sat" yang berarti benar. Satya mempunyai pengertian segala sifat-sifat yang menjungjung kebenaran dan kejujuran.Dalam perkembangan lebih lanjut dapat diartikan kesetiaan, ketaatan, dan ketekunan dalam segala bidang.Dalam Agama Hindu dikenal Panca Satya. Adapun bagian dari Panca Satya sebagai berikut:

1. satya Hredaya yaitu setian pada pikiran diri sendiri, kata hati, berpendirian teguh;

2. satya Wacana yaitu setia pada ucapan;

3. satya Semaya yaitu setia padan janji;

4. satya Mitra yaitu setia pada teman;

5. satya Laksana yaitu setia pada perbuatan. (Tim Penyusun Ganesa Exact Bandung, 1996: 45).

Jadi dapat disimpulkan bahwa kesetiaanmerupakan sikap atau prilaku setia terhadap sesuatu yang tidak akan pernah diingkari dan dihianati. Mengenai nilai kesetian yang terdapat dalam Geguritan Maniguna yaitu adanya Satya Mitra.

Mengenai nilai kesetian dalam Geguritan Maniguna terdapat ketika kesetiaan wanita terhadap suaminya terlihat ketika Diah Arini yang ditinggal pergi oleh suaminya, kemudian ada seorang raja bernama Raja Naranata yang hendak menjadikannya istri. Sang Raja sanggup memberikan kemewahan yang ada di istana, namun Diah Arini tidak tergoda dengan kemewahan yang ada. Dia tetap setia terhadap suaminya, dan pada waktu suaminya meninggal karena dibunuh oleh Raja Naranata, Diah Arini tetap setia menemani dan mengobati suaminya. Sikap Diah Arini mencerminkan sosok wanita yang memiliki kesetiaan yang tinggi terhadap suaminya, meskipun suaminya telah meninggal tetapi dia tetap ingin bersama. Hal ini dapat dilihat pada kutipan berikut:

katingalan sang apejah, mangalintik ri so ring puspa mararik, raris sang dyah amahayu ngusap-usap raga, wastra lukar inangkeban sampun puput, kalih kanin wus jinampyan, antuk ganten Sang Dyah arini.(Geguritan Maniguna Pupuh Pangkur, bait 28)

tan mari masasambatan, kadi cucur engkak-engkak ngasih asih, Layone tan sah karumrum, Sarwi ngugah maguyang, inggih kaka boya cingak tityang ratu, Sapasira gawah tityang, Iriki ring wana sepi.(Geguritan maniguna Pupuh pangkur, bait 29)

lalu lalista matilar, nanging jantos ingwang ring titi gal-ugil, malih ring margane kebus, yadyan ring kama loka, Mangda tumut makaronan saleng tuntun, duh hyang Dasa Lokapala, Cingak tityang satyeng laki.(Geguritan maniguna Pupuh pangkur, bait 30)

Terjemahan:

dilihat jasad yang meninggal, terlentang dibawah bunga yang harum, lalu dyah Arini menangani, membersihkan badannya, kainnya terlepas lalu kembali ditutupi, dan lukanya sudah dijampi, dengan kunyahan tembakau dyah Arini(Geguritan Maniguna Pupuh Pangkur, bait 28).

selalu memanggil-manggil, seperti burung tadah asih suaranya mamelas, jasadnya selalu dicumbu rayu, dan dan digugah terlena ditanah, duhai kakanda tidakah melihat aku ya Tuhan, siapakah yang menemani aku/ disini di hutan yang sepi (Geguritan Maniguna Pupuh pangkur, bait 29). 
sampai hati meninggalkan, tetapi tunggulah aku pada titi ugal-agil, dan pada jalan yang panas, walaupun di neraka, supaya turut berduaan saling bergandengan, ya Tuhan penguasa perjuru Dunia, lihatlah hambamu yang setia pada suami (Geguritan Maniguna Pupuh pangkur, bait 30)

Dari kutipan diatas menggambarkan kesetian Diah Arini terhadap Maniguna, ketika Diah Arini melihat jasad Maniguna dihutan, Diah Arini membersihkannya, jasadnya langsung dipeluk sambil menangis telah ditinggal pergi oleh orang yang disayanginya. Dengan rasa sedih Diah Arini memanggil-manggil Tuhan dan memohon agar ikut diajak meninggal. Sambil mengobati luka suaminya Diah Arini mengatakan ketika Diah Arini meninggal, agar mereka berdua dipertemukan meskipun mereka tinggal dineraka mereka tetap ingin bersama ada disana saling bergandengan tangan.Dia mengatakan bahwa dirinya benar-benar setia dengan suaminya sampai sehidup semati.

Kesetiaan berikutnya Diah Arini kembali teruji, terlihat dari ketika Raja Canda terpesona pada kecantikan Diah Arini dan berniat untuk memperistrinya. Oleh sebab itulah Sang Raja membunuh Maniguna dan membawa Diah Arini pulang ke istananya. Sang Raja mencoba merayu Diah Arini dengan berbagai cara, namun Diah Arini tidak tergoda dengan rayuan Sang Raja. Di dalam hatinya Diah Arini selalu memikirkan keadaan suaminya yang telah dibuang ketengah laut oleh Raja Canda, karena rasa sayang dan cintanya terhadap suaminya. Dapat dilihat dalam kutipan berikut:

dyah Arini sayan merang, eling ri pejah sang swami, sampun anyud ring sagara, kebus idepe luwir apui, kabatek satyeng laki, raris dane ngunus duhung, mijil geni anngorob, kawegan Sang Narapati, tur kasuduk, sang nata geseng saksana. (Geguritan Maniguna, Pupuh sinom bait 14) tan mari masasambatan, mangane sang sampun lalis, Cingak tityang duhka bara, iriki ring wana giri, lalutan sih Hyang Widhi, maweh lara tan awanuh, kewala patutuhang, mangde panggih sang alalis, Inggih ratu suka mati makaronang.(Geguritan Maniguna, Pupuh Sinom bait 16)

Terjemahan:

dyah Arini makin marah, teringat dengan wafatnya Sang suami, yang telah dihayutkan dilautan, pikirannya panas bagaikan api, kalena setia kepada suami, lalu Sang Dyah mencabut keris, keluar api berkobar, gelagapan Sri paduka raja, lalu ditusuk, Sang Nata terbakar seketika(Geguritan Maniguna, Pupuh sinom bait 14).

tiada hentinya mengigau, memikirkan orang yang sudah tiada, lihatlah aku duka lara nestapa, disini dalam hutan gunung, lalu terlalu tidak diberkati tuhan, memberikan duka lara tak habishabisnya, mohon ditunjukkan, agar kuberjumpa dengan orang yang sudah tiada, ya Tuhanku, lebih baik mati berduaan (Geguritan Maniguna, Pupuh sinom bait 16).

Dari kutipan diatas dapat dilihat kesetian Diah Arini terhadap suaminya kembali diuji. Dengan rayuan Sang Raja, Diah Arini tetap berpegangan teguh dengan hatinya. Bahkan Diah Arini marah dan dendam ketika teringat suaminya telah dibunuh dan mayatnya dibuang ke laut oleh Raja Canda. Lalu Maniguna langsung membunuh Raja Canda dengan menggunakan keris. Setelah Sang Raja dapat dibunuh, Diah Arini langsung melarikan diri kehutan menuju laut tempat suaminya dibuang. Sambil diperjalanan Diah Arini menangis sambil memohon kepada Tuhan agar dirinya bisa diberi petunjuk jalan dan dipertemukan dengan jasad suaminya dan Diah Arini memohon agar mereka berdua sama-sama 
meninggal.Dia tidak sanggup hidup sendirian menahan sedih.

\section{PENUTUP}

Tuhan memberikan anugerah yang dapat dialami oleh setiap orang, hal ini tergantung dari perbuatan kita masingmasing. Jika perbuatan kita baik maka karma yang didapatkan juga baik, dan jika perbuatan kita jahat maka karma yang didapatkan buruk. Demikianlah nilai Religius yang terdapat dalam Geguritan Maniguna melalui beberapa kejadian-kejadian yang telah diceritakan Berdasarkan penjelasan diatas, bahwa cerminan sikap yang dimiliki oleh Diah Arini untuk dapat dijadikan pedoman oleh masyarakat dan dapat mengajarkan kepada kita agar senantiasa setia terhadap pasangan, khususnya setia terhadap pasangan suamiistri.Jika kita sudah memiliki rasa setia terhadap pasangan kita, maka dapat menjalani kehidupan rumah tangga ini secara bersamasama baik dalam keadaan suka maupun duka dan dapat melanggengkan hubungan kita terhadap seseorang.

\section{Daftar Pustaka}

Bajrayasa, G. 1982. Dharma Proyek Pembinaan Mutu Pendidikan Agama Hindu dan Budha. Jakarta: Departemen Agama RI.
Punyatmadja. 1992. Panca Çradha. Jakarta: Yayasan Dharma Santi.

Purnami, Ida AyuPutu. 2006. Geguritan Maniguna Analisis Struktur dan Fungsi. Denpasar: Fakultas Sastra Universitas Udayana

Rustini, Ni Nyoman. 2012. Kajian Nilai Kesetiaan Dalam Geguritan Dewi Sakuntala.Skripsi. Denpasar: Institut Hindu DarmaNegeri Denpasar.

Tim Penyusun, 2008. Kamus Besar Bahasa Indonesia Pusat Bahasa. Jakarta: Pt Gramedia.

Upadesa, 1989.Tentang Ajaran-Ajaran Agama Hindu.Yayasan Dharma Sarathi.

Warna.I Wayan dkk.1991. Kamus Bali Indonesia. Denpasar: Dinas Pengajaran Propinsi Daerah Tingkat I Bali.

Yudha Triguna, Ida Bagus. 2010. Teori Tentang Simbol. Denpasa: Widya Dharma. 